\title{
Estimation of Kinetic Parameters for Five Lump Fluid Catalytic Cracking Riser Reactor
}

Kpalap, Emmanuel Kilsibari, Dagde, Kenneth Kekpugile*, Ehirim, Emmanuel Odianyegbuehua Department of Chemical/Petrochemical Engineering, Rivers State University, Port Harcourt, Nigeria

\section{Article History}

Received: 18.09.2020

Accepted: 05.10.2020

Published: 30.10 .2020

Journal homepage:

https://www.easpublisher.com/easjecs

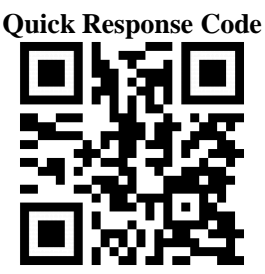

Abstract: An algorithm for the estimation of the kinetic parameters using five lump kinetic schemes for Fluid Catalytic Cracking of Vacuum Gas Oil has been developed. The optimization models were also developed using single point regression analysis to predict the pre-exponential function and activation energies. The mathematical models for the riser reactor were also developed to predict the yields of the various components. Mathematical models were integrated numerically using the fourth order runge-kutta algorithm. The optimization models were solved using Matlab version 8.4. Model predictions from the optimization model were, for activation energies $\mathrm{E}_{\mathrm{i}} ; 36.9920 \mathrm{~kJ} / \mathrm{mol}, 44.8125 \mathrm{~kJ} / \mathrm{mol}$, $41.8250 \mathrm{~kJ} / \mathrm{mol}, 52.5800 \mathrm{~kJ} / \mathrm{mol}, 57.2977 \mathrm{~kJ} / \mathrm{mol}, 56.5128 \mathrm{~kJ} / \mathrm{mol}, 50.5800 \mathrm{~kJ} / \mathrm{mol}$ and preexponential function $\mathrm{k}_{\mathrm{i} 0} ; 0.0017400 \mathrm{~s}^{-1}, 0.00002160 \mathrm{~s}^{-1}, 0.00002024 \mathrm{~s}^{-1}, 0.00055195 \mathrm{~s}^{-1}$, $0.00006234 \mathrm{~s}^{-1}, 0.000017464 \mathrm{~s}^{-1}, 0.002542400 \mathrm{~s}^{-1}$ with a maximum deviation of $30 \%$. The yield from the riser model showed gasoline as been the most obtained essential product and lesser coke formation compared to the yields obtained without optimization.

Keywords: Kinetic Parameter Estimation, Fluid Catalytic Cracking, Riser Reactor, Lumping Scheme, Gas oil.

Copyright (C) 2020 The Author(s): This is an open-access article distributed under the terms of the Creative Commons Attribution 4.0 International License (CC BY-NC 4.0) which permits unrestricted use, distribution, and reproduction in any medium for non-commercial use provided the original author and source are credited.

\section{INTRODUCTION}

The estimation of kinetic parameters can be said to be the judgement of the worth of measurement of factors that defines a system or operating conditions with regards to the rate of chemical processes and reactions. This goes into investigation of the factors or conditions that influences the rate and speed of a chemical reaction and give vital information about the reaction process and as well develop mathematical models that describes the reaction process [1].

One of the major branches of Chemical Engineering is Chemical Reaction Engineering which deals with chemical reactor and their design, especially the application of chemical kinetics to industrial systems. Chemical kinetics which is also known as Reaction kinetics deals with the study of chemical processes and reaction rate, which is the analysis of factors that affects speed of a chemical reaction, forming mathematical model to predict and describe a chemical reaction and understanding reaction mechanism [2].

The major challenge in lumping modeling is optimization of parameters [3]. Optimization in Engineering is concerned with selecting the best among the entire set by efficient quantitative methods [4]. The objective of the optimization is the use of specific methods to ascertain the best parameters and efficient solution to a design or reaction process. This solution technique is one of the best quantitative tools in industrial decision making [5].

The current day refineries have many units; of which Fluid Catalytic Cracking (FCC) unit are one of them and the major unit of these refineries. Fluid Catalytic Cracking is a chemical process and vital process in the refining of petroleum which uses heat and catalyst to break and convert long chain hydrocarbons into smaller chain hydrocarbons. Cracking of petroleum hydrocarbons was first done by the used of heat alone, but has been completely replaced by the used of heat and catalysts which has proven to produce more gasoline with high octane rating [6]. The product of catalytic cracking includes; Liquefied petroleum gas, light and heavy fuel oil, fuel gases, diesel fuel, high octane gasoline which is one of the main product that is desired from the FCC unit[7].

The aim of this research is to estimate the Kinetic Parameters of a Fluid Catalytic Cracking Riser Reactor of Port Harcourt Refinery Company (PHRC) using Five (5) Lump Kinetic Schemes. The production rate of the riser reactor of FCC unit will remain the 
same for years if the reaction is not optimized and the efficiency of the riser reactor improved which is one of the major factors that affect the production of gasoline. Hence, kinetic model of FCC riser reactor and the parameters of the reaction have to be developed and estimated to improve overall efficiency and a small improvement in the operation of the FCC riser reactor can result in impressive economic benefits.

Researchers have done several works on Fluid Catalytic Cracking (FCC) unit. Yakubu et al., [8] researched on Parameter estimation of a six-lump kinetic model of an industrial Fluid Catalytic Cracking reactor. They developed and simulated a steady state model of an industrial Fluid Catalytic Cracking (FCC) reactor with a proposed six-lumped kinetic model to estimate the following parameters; Frequency factors, activation energies and heats of reaction for the catalytic cracking kinetics using a model based parameter estimation technique along with data from an industrial FCC reactor in Sudan. The new six-lump model was implemented on gPROMS software to crack gas oil.

Souza et al., [9] carried out work on Thermodynamic optimization of Fluidized Catalytic Cracking (FCC) reactor. They developed a thermodynamic optimization procedure for FCC riser reactor, were the formulation made used of a $2 \mathrm{D}$ fluid flow and kinetic model to provide the necessary information for the optimization process. The thermodynamic analysis was based on the minimization of the destroyed exergy in the system. According to their verifications, for any given catalyst mass flow rate, there exists an optimum value for the catalyst to oil mass flow rate ratio (COR) and the optimization was done based on the catalyst to oil ratio.

Sheth and Babu, [10] worked on Optimization of Kinetic Parameters in Pyrolysis of Biomass Using Logarithmic Differential Evolution (LDE). They proposed a kinetic model where the kinetic scheme of biomass decomposition by two competing reactions giving gaseous volatiles and solid charcoal was used and based on different possible relation of activity of biomass with normalized conversion, four other models were developed. Estimation was done on the obtained parameters by minimizing the square of the error between the experimental data of thermo-gravimetry of hazelnut shell and simulated model, predicting values of residual weight fraction using Differential Evolution, which is a population based search algorithm. Out of the four models developed, three models gave corresponding result with the experimental data.

The development of Models for Fluid Catalytic Cracking Fluidized Bed Reactor Using Four-Lump Kinetic Scheme have been done by Dagde and Akpa [11], where they developed models for plug flow-plug flow combination process and plug flow-continuous stirred tank reactor (CSTR) process and compared their rate of conversion of gasoil. Their result showed that the plug flow-plug flow combination process gave a higher conversion of gasoil. The reactor here was modelled as a fluidized bed reactor, using four lump kinetic schemes to describe the Fluid Catalytic Cracking reaction process in the reactor and a two phase hypothesis consisting of emulsion and bubble phase were used to describe the fluidized bed models.

Yakubu et al., [12] researched on Optimization of Fluidized Catalytic Cracking Unit Regenerator to Minimize $\mathrm{CO}_{2}$ Emissions. The work deals majorly on minimizing $\mathrm{CO}_{2}$ emission from the regenerator reactor in other to solve the problem of global warming. The solution technique was model based, where the regenerator bed was modelled as a perfectly mixed reactor, where there was no temperature gradient consideration in the bed. The emulsion phases for energy and coke balances were modelled as a CSTR while the bubble phase for the gas component balance was modelled as a Plug Flow Reactor. Partial differential equations were used for the component balance equations for the gaseous phases in emulsion and bubble.

Most of the works done on FCC unit has to do with just modelling, design and simulation. Yakubu et al., [8] actually did a good work on Parameter estimation (activation energies, rate constants etc.) of a six-lump kinetic model of an industrial Fluid Catalytic Cracking reactor, but didn't consider the estimation of the pre-exponential factor. Where as in this work, the estimation of pre-exponential factor will be considered and the lumping system is different from the previous. This is to say the number of lumps maybe the same but the nature of the lumping might be different. For instance the six lump kinetic schemes of Mu et al., [13] are totally different from the six lump kinetic schemes of Souza et al., [9].

Dagde and Puyate [14] did an extensive work on the modelling and Simulation of industrial FCC reactor, where the analysis was bases on five-lump kinetic scheme but the kinetic parameters such as Activation energies, Pre-exponential factor, Rate Constant etc., were not estimated to get the optimum values.

Souza et al., [9] did no estimation on the kinetic parameters of FCC riser reactor. Their major interest was on the thermodynamic analysis of the system.

\section{MATERIALS AND METHODS Materials}

This deals with material components to apply in the method of the models for FCC Riser reactor. This work does not involve experimental techniques; hence model equations relating to the fundamental of the five 
lump kinetic schemes will be applied appropriately. The feed for cracking process is Vacuum Gas Oil (VGO). The materials adopted for this research are five-lump reaction network for the cracking of vacuum gas oil on FCC Riser Reactor, Optimization tool (Single Point Regression Analysis), F-table, Principle of Conservation of Energy and Mass, Thermodynamic data and Literature data from FCC unit at Port Harcourt Refinery Company (PHRC Ltd), Eleme.

\section{Methods}

The method applied in this research work was the development of the mass (mole fraction) and Energy models in a riser reactor and the derivation of the Kinetic models of the five-lump network of gas oil on FCC unit. The formulation of the optimization models on the riser with the aim of optimizing the rate constants, pre-exponential factors and activation energies of the lumps.

\section{Kinetic Model}

The performance of the FCC units plays a major role in the overall economics of petroleum refining plants. A small improvement in the operation of an FCC riser reactor can result in impressive economic benefits. However, these can be achieved only if a satisfactory material model is available, which is analytical so that its optimization can lead to optimal operating conditions. The development of kinetic model of the five-lump Fluid Catalytic Cracking unit (FCC) is essential for the modelling of the riser reactor, reactor design and for the optimization of the rate constants etc. Table 3.1 shows the lump of the hydrocarbon and the boiling point range at 1atm [15].

Table-1: Range of Hydrocarbon and Boiling Point for the lumps [15]

\begin{tabular}{|l|l|l|}
\hline Lump & Range of Hydrocarbon & Boiling Point Range ${ }^{\mathbf{0}} \mathbf{C}$ \\
\hline Fuel Gas & $\mathrm{C}_{1}-\mathrm{C}_{2}$ & $<36$ \\
\hline Liquefied Petroleum Gas (LPG) & $\mathrm{C}_{3}-\mathrm{C}_{4}$ & $>36$ \\
\hline Gasoline & $\mathrm{C}_{5}-\mathrm{C}_{12}$ & $36-216$ \\
\hline Vacuum Gas Oil (VGO) & $\mathrm{C}_{12}-\mathrm{C}_{20}$ & $216-342$ \\
\hline Coke & $>\mathrm{C}_{20}$ & $>342$ \\
\hline
\end{tabular}

The network for the five-lump; vacuum gas-oil, gasoline, LPG, dry gas and coke taking place in FCC-Unit riser is shown in Figure 1.

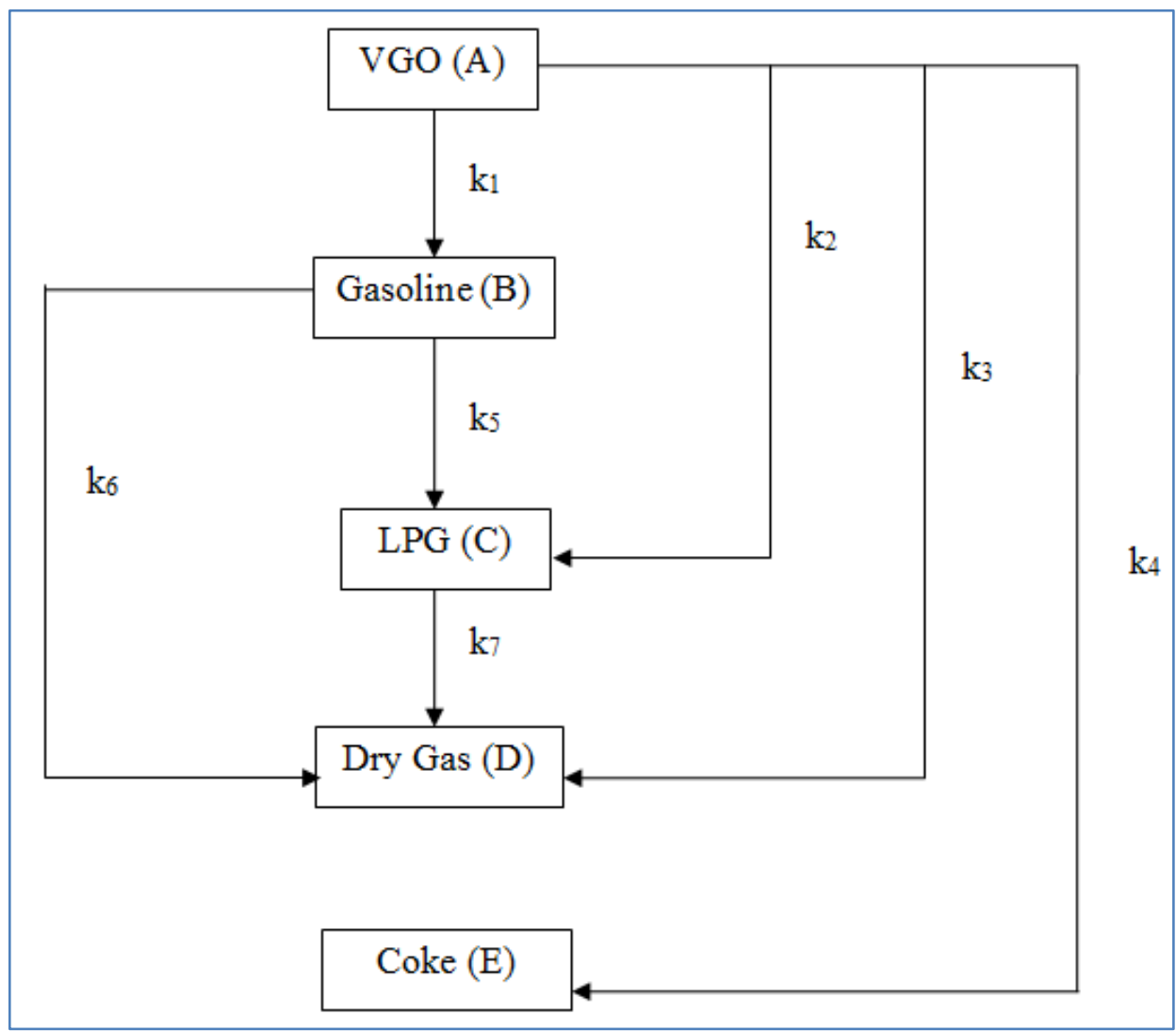

Fig-1: Five-lump Network for the FCC of Vacuum Gas Oil 
According to Dagde et al. [16], the rate models are developed considering the effectiveness factor, $\eta_{s s}$ and in terms of mole fraction as follows;

$$
\begin{aligned}
\left(-r_{A}\right)= & k_{1} y_{A}^{2} \emptyset \eta_{s s}+k_{2} y_{A}^{2} \emptyset \eta_{s s}+k_{3} y_{A}^{2} \emptyset \eta_{s s}+k_{4} y_{A}^{2} \emptyset \eta_{s s} \\
= & \left(k_{1}+k_{2}+k_{3}+k_{4}\right) y_{A}^{2} \phi \eta_{s s} \\
\left(-r_{B}\right)= & k_{5} y_{B} \emptyset \eta_{s s}+k_{6} y_{B} \emptyset \eta_{s s}-k_{1} y_{A}^{2} \emptyset \eta_{s s} \\
= & \left(\left(k_{5}+k_{6}\right) y_{B}-k_{1} y_{A}^{2}\right) \phi \eta_{s s} \\
\left(-r_{C}\right)= & k_{7} y_{C} \emptyset \eta_{s s}-k_{5} y_{B} \emptyset \eta_{s s}-k_{2} y_{A}^{2} \emptyset \eta_{s s} \\
& =\left(k_{7} y_{C}-k_{5} y_{B}-k_{2} y_{A}^{2}\right) \phi \eta_{s s} \\
\left(-r_{D}\right)= & -k_{6} y_{B} \emptyset \eta_{s s}-k_{7} y_{C} \emptyset \eta_{s s}-k_{3} y_{A}^{2} \emptyset \eta_{s s} \\
& =-\left(k_{6} y_{B}+k_{7} y_{C}+k_{3} y_{A}^{2}\right) \phi \eta_{s s} \\
\left(-r_{E}\right)= & -k_{4} y_{A}^{2} \emptyset \eta_{s s}
\end{aligned}
$$

where; $k_{1}, k_{2}, k_{3}, k_{4}, k_{5}, k_{6}$ and $k_{7}$ are the respective rates constants, considered in the reaction network, $\phi$ is the catalyst deactivation function, $\eta_{s S}$ is the effectiveness factor, $r_{A}, r_{B}, r_{C} r_{D}$ and $r_{E}$ are the rate of reaction for the cracking of gas-oil and information of products, $y_{A}, y_{B}, y_{C}, y_{D}$ and $y_{E}$ are the mole fraction for; gas oil (A), gasoline (B) liquefied petroleum (C), fuel gas (D), and Coke (E).

The reaction rate constant is dependent on temperature, as given by Arrhenius equation;

$k_{i}=k_{i, 0} \exp \left[\frac{-E_{i}}{R T}\right]$

where; $\quad k_{i, 0}=$ Pre-exponential factor of ispecies $\left(\mathrm{S}^{-1}\right), E_{i}=$ Activation Energies of i-species, $\mathrm{kcal} / \mathrm{mol}, \mathrm{R}=$ Gas Constant, $\mathrm{kcal} / \mathrm{mol}^{\circ} \mathrm{F}$

\section{Riser Reactor Model (Plug Flow Reactor) \\ Development \\ Model Assumption}

The following assumptions were made in developing the models:

i. Only one-dimensional flow of materials and energy occurs in the riser reactor without axial/radial flow (Han and Chung [17], Gupta \&Rao [18] and Ahari et al. [19], Han and Chung [17], Gupta \& Rao [18] and Ahari et al. [19],

ii. The riser reactor will be modeled adiabatically
(6)

iii. The viscosities, densities and heat capacities of the species are constant throughout the flow process.

iv. Dispersion and adsorption process within the catalyst particles are very negligible.

v. Due to the static head of catalyst in the riser, there is pressure change throughout

vi. Fluid flow will not be affected as a result of coke deposed on the catalyst.

vii. Constancy of temperature for both catalyst and gas in the riser.

Figure 2 depicts a hypothetical representation of a riser reactor modeled as Plug Flow indicating a differential volume where; $\rho_{i}$ and $d \rho_{i}$ are the inlet densities, $V_{R}$ is volume of reactor, $\mathrm{Z}$ is the reactor length, $v_{0}$ is volumetric flowrate.

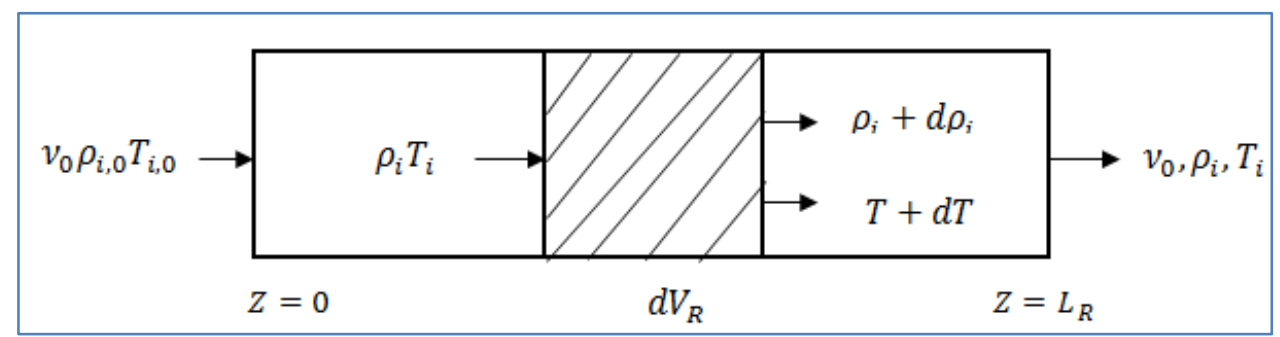

Fig-2: Hypothetical Sketch of a Plug Flow Reactor (seen as a riser reactor)

The material balance for the riser reactor is given as;

$\left\{\begin{array}{c}\text { Rate of mass } \\ \text { accumulated } \\ \text { within the riser }\end{array}\right\}=\left\{\begin{array}{c}\text { Rate of mass } \\ \text { inflow into } \\ \text { the riser }\end{array}\right\}-\left\{\begin{array}{c}\text { Rate of mass } \\ \text { outflow into } \\ \text { the riser }\end{array}\right\}-$ 
(Rate of depletion of $)$

mass due to chemical

reaction with the riser

Applying appropriate terms into equation (7) and simplifying gives;

$\frac{d y_{i}}{d z}=\left(-r_{i}\right) \varepsilon_{R} \frac{\rho_{g R} A_{R} L_{R}}{F_{g R}}$

\section{Coupling the rate expression gives;}

$\begin{array}{rlrl}\frac{d y_{A}}{d Z} & =-\varepsilon_{R} \frac{\rho_{g R} A_{R} L_{R}}{F_{g R}} & & \left(k_{1}+k_{2}+k_{3}+k_{4}\right) y_{A}^{2} \phi \\ \frac{d y_{B}}{d Z} & =-\varepsilon_{R} \frac{\rho_{g R} A_{R} L_{R}}{F_{g R}} & & {\left[\left(k_{6}+k_{5}\right) y_{B}-k_{1} y_{A}^{2}\right] \phi} \\ \frac{d y_{C}}{d Z} & =-\varepsilon_{R} \frac{\rho_{g R} A_{R} L_{R}}{F_{g R}} & & \left(k_{1} y_{C}-k_{5} y_{B}-k_{2} y_{A}^{2}\right) \phi \\ \frac{d y_{D}}{d Z}=-\varepsilon_{R} \frac{\rho_{g R} A_{R} L_{R}}{F_{g R}} & & {\left[-\left(k_{6} y_{B}+k_{7} y_{C}+k_{3} y_{A}^{2}\right)\right] \phi} \\ \frac{d y_{E}}{d Z}=-\varepsilon_{R} \frac{\rho_{g R} A_{R} L_{R}}{F_{g R}} & & \left(-k_{4} y_{A}^{2}\right) \phi\end{array}$

where for riser;

$\phi=\exp [-\alpha \tau]$

$\alpha=\alpha_{0} \exp \left[-\frac{E}{R T}\right]$

$\tau=\frac{L_{R} Z \rho_{g R} A_{R}}{F_{g R}(C T O)}$

$\phi=\exp \left[-\frac{\alpha L_{R} Z \rho_{g R} A_{R}}{F_{g R}(C T O)}\right]$

\section{The Energy Model}

The law of conservation of Energy was applied on differential volume of the reactor to determine the temperature distribution gives:

$\left\{\begin{array}{c}\text { Rate of Accumulation } \\ \text { of Energy within } \\ \text { the riser }\end{array}\right\}=\left\{\begin{array}{c}\text { Rate of inflow } \\ \text { of energy into } \\ \text { the riser }\end{array}\right\}-\left\{\begin{array}{c}\text { Rate of outflow of } \\ \text { energy from the differential } \\ \text { the riser }\end{array}\right\}-$

$\left\{\begin{array}{c}\text { Rate of depletion of } \\ \text { mass due to chemical } \\ \text { reaction with the riser }\end{array}\right\}$

Applying appropriate terms into equation (18) and simplifying gives;

$-\frac{d T_{R}}{d z}=\frac{\sum_{i=1}^{n}\left(\Delta H_{r, i}\right)\left(-r_{i}\right) \rho_{g R} \varepsilon_{R} A_{R} d l}{\left(F_{g R} C p_{g R}+F_{c a t} C p_{c a t}\right) T_{r e f}}$

where; $\sum_{i=1}^{n}\left(\Delta H_{r, i}\right)\left(-r_{i}\right)$ is the heat of reaction per unit mass of gas oil due to catalytic cracking for the various species obtain and is given as;

$\sum_{i=1}^{n}\left(\Delta H_{r, i}\right)\left(-r_{i}\right)=\left(k_{1} \Delta H r_{1}+k_{2} \Delta H r_{2}+k_{3} \Delta H r_{3}+k_{4} \Delta H r_{4}\right) y_{A}^{2} \phi+\left(k_{5} \Delta H r_{5}+k_{6} \Delta H r_{6}\right) y_{B} \phi+k_{7} \Delta H r_{7} y_{C} \phi$

Let

$$
\begin{aligned}
& \eta=k_{1} \Delta H r_{1}+k_{2} \Delta H r_{2}+k_{3} \Delta H r_{3}+k_{4} \Delta H r_{4} \\
& \varphi=k_{5} \Delta H_{r, 5}+k_{6} \Delta H_{r, 6} \\
& \omega=k_{7} \Delta H_{r, 7}
\end{aligned}
$$

Combining (20) and (21) into (19) yields;

$-\frac{d T_{R}}{d Z}=\frac{\left(\eta y_{A}^{2}+\varphi y_{B}+\omega y_{C}\right) \rho_{g R} \varepsilon_{R} A_{R} l_{R} \phi}{\left(\mathrm{F}_{g R} C p_{g R}+\mathrm{F}_{c a t} \mathrm{Cp}_{c a t}\right) \mathrm{T}_{r e f}}$

\section{Optimization Model for the Kinetic Parameter Estimation}

The kinetic parameters (Pre-exponential factors, $\mathrm{A}_{\mathrm{i}}$; Activation Energies, $\mathrm{E}_{\mathrm{i}}$; and Rate 'Constants, $\mathrm{k}_{\mathrm{i}}$ ) are estimated and optimized using the following models by minimizing the objective function, $\mathrm{S}$; subject to the constraints values, $y_{\mathrm{i}, 0}, T_{\text {Ref }}$.

Objective function: 
$S=\left(\sum_{j=1}^{m}\left(y_{\mathrm{j}, \text { lit }}-y_{\mathrm{j}, \mathrm{Cal}}\right)^{2}+\left(\mathrm{T}_{R, \mathrm{lit}}-\mathrm{T}_{R, \text { cal }}\right)^{2}\right)$

Where; $\mathrm{m}=$ number of species, $\mathrm{A}, \mathrm{B}, \mathrm{C}, \mathrm{D}$, and $\mathrm{E}$

$j=1 \ldots 5, y_{\mathrm{j}, \mathrm{lit}}$ is the mole fraction of $j$-component obtained from literature data, $y_{\mathrm{L} C a l}$ is the mole fraction of $j$ -

component obtained from the simulation, $\mathrm{T}_{R, \mathrm{lit}}$ is the temperature obtained from literature, $\mathrm{T}_{R, c a l}$ is the temperature obtained from the simulation results.

Subject to (Constraint) models;

$y_{\mathrm{j}, \text { lit }}, T_{R, l i t}$

$y_{\mathrm{j}, \text { lit }}<0$

$T_{R, l i t}<0$

The incremental change $\Delta$ s will be obtained as;

$\Delta \mathrm{s}=-\left[\left[\begin{array}{lll}n & \times & p\end{array}\right]\left[\begin{array}{lll}p & x & n\end{array}\right]^{-1}\left[\begin{array}{lll}n & \times & p\end{array}\right]\right.$

Where; $[\mathrm{n} \times \mathrm{p}]=$ the matrix of $\mathrm{n}$-iterations by $\mathrm{p}$-components

$[\mathrm{p} \times \mathrm{n}]=[\mathrm{m} \times \mathrm{p}]^{\mathrm{T}}=$ the matrix transpose.

Thus, Optimization model for the kinetic parameter estimation are thus;

$E i^{(z+1)}=E i^{(z)}+\alpha \Delta s$

$K i^{(z+1)}=K i^{z}+\alpha \Delta s$

$A i^{(z+1)}=A i^{z}+\alpha \Delta s$

where; $\alpha=$ fractional ranges; $0<\alpha<1$ (usually as $\alpha=0.82$ ), $\mathrm{n}$ is the number of iteration (which is 10 ), $\mathrm{p}$ is the number of variables (which is 7 ), $\Delta \mathrm{s}$ is the Incremental change, $\alpha$ is the step size.

The criteria for convergence;

$F_{c a l} \geq \mathrm{F}_{t a b}$

If $F_{c a l} \geq \mathrm{F}_{t a b}$, stop iteration and compute the results which are the activation energy value obtained, else continue iteration till $F_{c a l} \geq \mathrm{F}_{\text {tab }}$

where;

$\mathrm{F}_{c a l}=\frac{M S M}{M S E}$

MSM is the Mean of Square Mean $=\frac{\text { Sum of Square Mean }}{\mathrm{P}-\text { Components }}$

And MSE is the Mean of Square Error $=\frac{\text { Sum of Square Error }}{(\mathrm{n}-\mathrm{p}) \Rightarrow \text { Degreeof Freedom }}$

$\mathrm{F}_{t a b}=$ determined at $95 \%$ confidence level.

The optimised rate constant values were obtained from the Arrhenius equation; $k_{i}=$ $k_{i, 0} \exp \left(\frac{-E_{i}}{R T}\right)$ which was used to obtain the optimised mole fractions and temperature values of the various species

\section{Kinetic Parameter Estimation Procedures}

This was carried out with the aim of optimising some kinetic parameters suitable for the improvement and maximization of the desired product. The optimised values were considered to be the best values between plant/literature/experimental data and the model calculated values. The estimation of kinetic parameters in this work was based on the optimization technique of single point regression analysis using Matlab which makes complex non-linear models easier to solve. The riser model equations consist of sets of non-linear first order differential equations which were integrated numerically using the fourth order Runge-
Kutta algorithm and then subjected to the following optimization technique steps:.

a. Runge-kutta $4^{\text {th }}$ order algorithm will be used to solve the steady state mole fraction and temperature models with the aid of computer programming software (Matlab).

b. The results from the simulation of the steady state mole fraction and temperature model were compared with the literature data with reasonable agreement.

c. The result from the simulation of the steady state mole fraction and temperature model were subjected to optimization (using single point regression analysis), still with the aid of MATLAB software. This where the objective function (s), which is a cost function was subjected to various constraints which were $y_{\mathrm{j}, \text { lit }}, T_{R, l i t}$ and acts as the boundary conditions. 
d. The optimal " $k_{i}$ " values obtained from $k_{i}=k_{i, 0} \exp \left(\frac{-E_{i}}{R T}\right)$ were used to obtain the optimal yields of the mole fractions and temperature of the various species. e. The optimized kinetic parameters (preexponential constants, activation energies and rate constants) were compared with the literature data to get percentage deviation.

\section{Operating Parameters}

Table-2: Kinetic Parameter for FCC five lumps reaction scheme [20]

\begin{tabular}{|l|l|l|l|}
\hline Parameters $\left(\mathbf{k}_{\mathbf{i}}\right)$ & $\begin{array}{l}\text { Activation } \\
\text { Energy, } \mathbf{E}_{\mathbf{i} \mathbf{0}}(\mathbf{k J} / \mathbf{m o l})\end{array}$ & $\begin{array}{l}\text { Pre-exponential } \\
\text { Constant, } \mathbf{k}_{\mathbf{i} \mathbf{0}}\left(\mathbf{s}^{-\mathbf{1}}\right)\end{array}$ & $\begin{array}{l}\text { Stoichiometric } \\
\text { Coefficient }(\mathbf{V})\end{array}$ \\
\hline Gas Oil to Gasoline, $\mathrm{k}_{1}$ & 46.240 & 0.002 & 3.2767 \\
\hline Gas Oil to LPG, $\mathrm{k}_{2}$ & 59.750 & 0.0000184 & 8.2655 \\
\hline Gas Oil to Dry Gas, $\mathrm{k}_{3}$ & 59.750 & 0.0000184 & 20.7527 \\
\hline Gas Oil to Coke, $\mathrm{k}_{4}$ & 59.750 & 0.000581 & 20.965 \\
\hline Gasoline to LPG, $\mathrm{k}_{5}$ & 78.490 & 0.00005566 & 2.5225 \\
\hline Gasoline to Dry Gas, $\mathrm{k}_{6}$ & 78.490 & 0.00002183 & 6.4022 \\
\hline LPG to Dry Gas, $\mathrm{k}_{7}$ & 59.750 & 0.003174 & 2.5380 \\
\hline Catalyst Decay & 117705 & 83806.556 & Lee et al., $[21]$ \\
\hline
\end{tabular}

Table-3: Average Molecular Weight of FCC five lumps [22]

\begin{tabular}{|l|l|}
\hline Lumps & Average Molecular Weight \\
\hline Gas Oil & $\mathrm{M}_{\mathrm{go}}=386^{* *}$ \\
\hline Gasoline & $\mathrm{M}_{\mathrm{g}}=117.8^{*}$ \\
\hline LPG & $\mathrm{M}_{1}=46.7^{*}$ \\
\hline Dry Gas & $\mathrm{M}_{\mathrm{d}}=18.4^{*}$ \\
\hline Coke & $\mathrm{M}_{\mathrm{c}}=400^{*}$ \\
\hline
\end{tabular}

Table-4: FCC Riser Reactor Feed and Products Properties [15]

\begin{tabular}{|l|l|l|l|l|}
\hline Components & $\begin{array}{l}\text { Flow-rate } \\
\text { (Kg/hr) }\end{array}$ & $\begin{array}{l}\text { Specific } \\
\text { Gravity }\end{array}$ & API Gravity & $\begin{array}{l}\text { Composition } \\
\text { (Weight \%) }\end{array}$ \\
\hline Gas Oil Feed & 244090 & 0.927 & 21.2 & 100 \\
\hline Fuel Gas & 13180 & - & - & 5.4 \\
\hline LPG (C3) & 15388 & - & - & 6.3 \\
\hline LPG (C4) & 26118 & - & - & 10.7 \\
\hline Gasoline & 112037 & 0.739 & 60.0 & 45.9 \\
\hline Light Cycle Oil & 43448 & 0.973 & 14.0 & 17.8 \\
\hline Bottoms & 21480 & 1.072 & 0.5 & 8.8 \\
\hline Coke & 12448 & - & - & 5.1 \\
\hline
\end{tabular}

Table-5: FCC Industrial Riser Reactor Dimensions [15]

\begin{tabular}{|l|l|}
\hline Parameter & Values (meters) \\
\hline Riser Length & 22.9 \\
\hline Riser Diameter & 2.9 \\
\hline Regenerator Length & 35.45 \\
\hline Regenerator Diameter & 9.8 \\
\hline Cyclone Height & 14.24 \\
\hline Cyclone Diameter & 1.5 \\
\hline Disengager Height & 24.5 \\
\hline
\end{tabular}

Table-6: FCC Industrial Riser Distilled-off Gas-oil Percentage and Corresponding Temperature-cuts [15]

\begin{tabular}{|l|l|l|}
\hline Percentage Distilled-off & ${ }^{\mathbf{0}} \mathbf{C}$ & ${ }^{\mathbf{0}}$ \\
\hline 10 & 349 & 622 \\
\hline 30 & 421 & 694 \\
\hline 50 & 449 & 722 \\
\hline 70 & 483 & 756 \\
\hline 90 & 532 & 804 \\
\hline
\end{tabular}




\section{Solution Techniques}

The model equations consisting of nonlinear first order differential equations were integrated numerically using the fourth order Runge-Kutta algorithm subject to the followingboundary conditions:

$\mathrm{Z}=0:\left\{\begin{array}{c}y_{A}=1 \\ y_{B}=y_{C} \\ T_{R}=780 K\end{array}=y_{D}=y_{E}=0\right.$

\section{RESULTS AND DISCUSSION}

Table 7 shows the results obtained from exponential constants and activation energies. The rate equation (27), (28) and (29); yielding the optimized pre-

Table-7: Optimize Kinetic Parameters (Pre-Exponential Constants; Activation Energies and Rate Constants) for Five Lumps kinetics scheme.

\begin{tabular}{|r|l|c|c|}
\hline \multicolumn{1}{|c|}{$\boldsymbol{i}$} & $\boldsymbol{k}_{\boldsymbol{i} \mathbf{0}}$ & $\boldsymbol{E}_{\boldsymbol{i}}$ & $\boldsymbol{k}_{\boldsymbol{i}}=\boldsymbol{k}_{\boldsymbol{i} \mathbf{0}} \mathbf{e x p}\left(-\frac{\boldsymbol{E}_{\boldsymbol{i}}}{\boldsymbol{R T}_{\boldsymbol{c a l}}}\right)$ \\
\hline $\mathbf{1 .}$ & 0.00174 & 36.992 & 0.00173 \\
\hline 2. & 0.0000216 & 44.8125 & 0.00002101 \\
\hline 3. & 0.00002024 & 41.825 & 0.00002011 \\
\hline 4. & 0.00055195 & 52.58 & 0.0005475 \\
\hline 5. & 0.00006234 & 57.2977 & 0.00006179 \\
\hline 6. & 0.000017464 & 56.5128 & 0.00001731 \\
\hline 7. & 0.0025424 & 50.7875 & 0.002523 \\
\hline
\end{tabular}

Table 8 shows the comparison between model predictions and literature data [14] for the rate constants, indicating reasonable agreement with a maximum percentage deviation of $20 \%$ and a minimum deviation of $5 \%$.

Table-8: Comparison of Optimized Rate Constant $\left(k_{i}\right)$ Value and Literature Value

\begin{tabular}{|c|l|c|c|}
\hline Parameter & \multicolumn{2}{|c|}{ Rate Constant $\left(\boldsymbol{k}_{\boldsymbol{i}}\right)$} & Deviation \\
\hline $\boldsymbol{i}$ & Literature & Optimize & \\
\hline 1 & 0.0020000 & 0.00173000 & 0.14 \\
\hline 2 & 0.00001824 & 0.00002101 & 0.15 \\
\hline 3 & 0.00001824 & 0.00002011 & 0.10 \\
\hline 4 & 0.0005760 & 0.0005475 & 0.05 \\
\hline 5 & 0.00005500 & 0.00006179 & 0.12 \\
\hline 6 & 0.0000216 & 0.00001731 & 0.20 \\
\hline 7 & 0.0031500 & 0.00252300 & 0.20 \\
\hline
\end{tabular}

Table 9 shows the comparison between model predictions and literature data [14] for the activation energies, indicating reasonable agreement with a maximum percentage deviation of $30 \%$ and a minimum deviation of $12 \%$.

Table-9: Comparison of Optimized Activation Energies $\left(E_{i}\right)$ Value and Literature Value

\begin{tabular}{|c|c|c|c|}
\hline Parameter & \multicolumn{2}{|c|}{ Activation Energies $\left(\boldsymbol{E}_{\boldsymbol{i}}\right)$} & Deviation \\
\hline $\boldsymbol{i}$ & Literature & Optimize & \\
\hline 1 & 46.240 & 36.992 & 0.20 \\
\hline 2 & 59.750 & 44.813 & 0.25 \\
\hline 3 & 59.750 & 41.825 & 0.30 \\
\hline 4 & 59.750 & 52.580 & 0.12 \\
\hline 5 & 78.490 & 57.298 & 0.27 \\
\hline 6 & 78.490 & 56.513 & 0.28 \\
\hline 7 & 59.750 & 50.788 & 0.15 \\
\hline
\end{tabular}

Table 10 shows the comparison between model predictions and literature data [14] for the preexponential constants, indicating reasonable agreement with a maximum percentage deviation of $20 \%$ and a minimum deviation of $5 \%$. 
Table-10: Comparison of Optimized Pre-Exponential Constant $\left(k_{i 0}\right)$ andLiterature Value

\begin{tabular}{|c|l|l|l|}
\hline Parameter & Pre-Exponential Constant $\left(\boldsymbol{k}_{\boldsymbol{i} \mathbf{0}}\right)$ & Deviation \\
\hline $\boldsymbol{i}$ & Literature & Optimize & \\
\hline 1 & 0.00200000 & 0.00174000 & 0.13 \\
\hline 2 & 0.00001824 & 0.0000216 & 0.18 \\
\hline 3 & 0.00001824 & 0.00002024 & 0.11 \\
\hline 4 & 0.000581 & 0.00055195 & 0.05 \\
\hline 5 & 0.00005566 & 0.00006234 & 0.12 \\
\hline 6 & 0.00002183 & 0.000017464 & 0.20 \\
\hline 7 & 0.00317400 & 0.002542400 & 0.20 \\
\hline
\end{tabular}

Where percentage deviation $=\left|\frac{\text { Literature-Optimize }}{\text { Literature Value }}\right| \times 100 \%$

\section{Results of Simulation}

Variation of Mole Fractions of Cracked Gas Oil to different Species (Gasoline, LPG, Dry Gas and

\section{Coke) along the Reactor}

Figure 4 shows the variation of mole fractions of cracked Gasoil to Gasoline, LPG, Dry Gas and Coke along the riser reactor bed height. The Gasoil was assumed as second order that was depleted by chemical reactions in the presence of Zeolite catalyst to give the various products (Gasoline, LPG, Dry Gas and Coke). The profiles of the depletion process of the Gasoil and formation of products are shown in Figure 4. The depletion profile is exponential along the riser bed height while the formation of the products occurred exponentially along the riser height. From Fig.4, initially the Gasoil was $y_{A}=1$, at $z=0 \mathrm{~m}$ and depleted to the final mole fraction (yield) of $y_{A}=$ 0.496 at $z=24 \mathrm{~m}$ meanwhile, the products mole fractions initially were respectively $y_{B}=y_{C}=y_{D}=$ $y_{E}=0$ for Gasoline, LPG, Dry Gas and Coke and increased to the respective yields of $y_{B}=0.4933 \mathrm{~mol} ; y_{C}=0.0177 \mathrm{~mol} ; y_{D}=0.0813 \mathrm{~mol}$; and $y_{E}=0.2937 \mathrm{~mol}$.

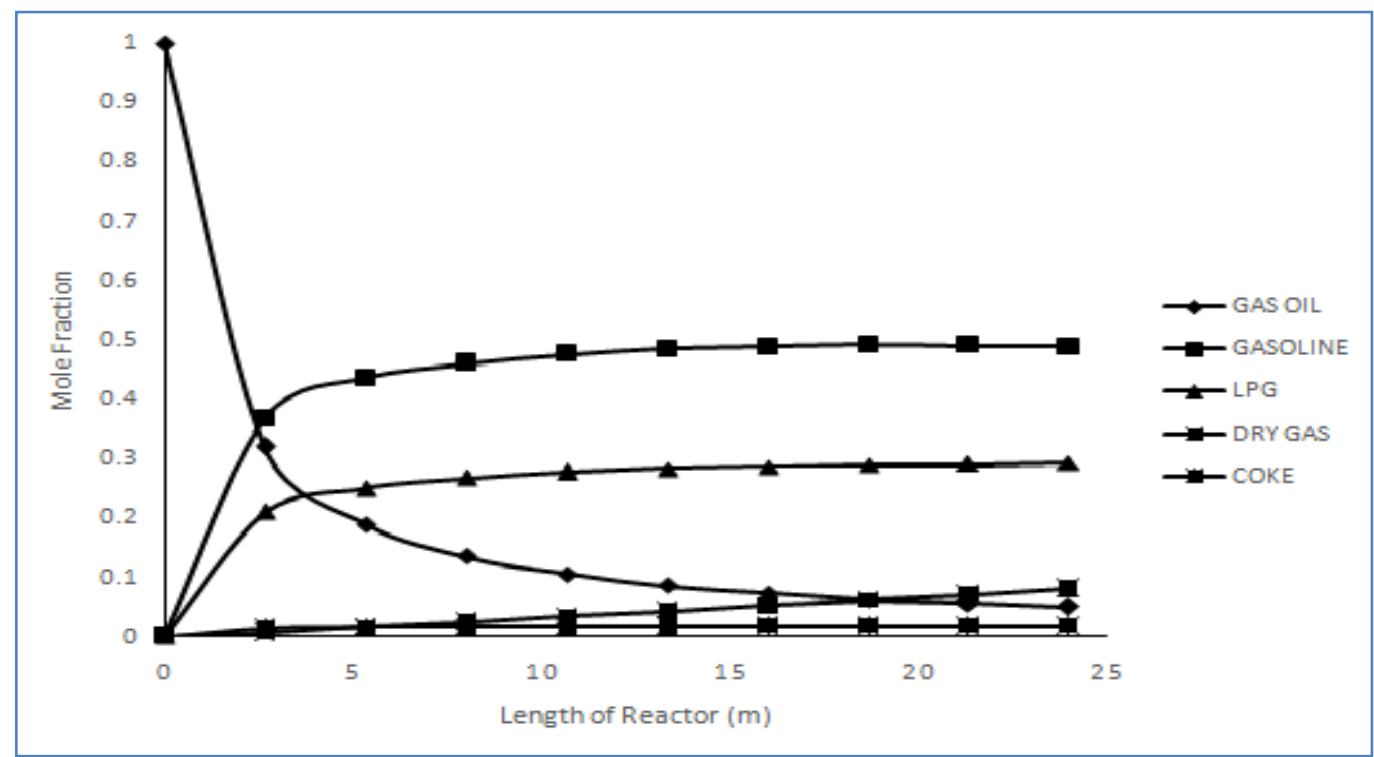

Fig-4: Profile of Mole Fractions of Cracked Gas Oil to different Species (Gasoline, LPG, Dry Gas and Coke) versus Length of Reactor

It should be noted that the yield of Gasoline, the most desired and economic product was the highest and least yield was obtained for coke. Coke deposition on the catalyst pore space reduced gasoline production due to its secondary cracking to other products. The products formation results were reasonable and good indicating that the models developed could be used to predict yields of products in Fluid Catalytic Cracking reactor. It was also shown that the yields for normal simulation was lower and more coke produced than optimization models results since the kinetic parameters were optimize and upgraded to produce good results. 


\section{Variation of Optimized Mole Fractions of Cracked Gasoil to different Species (Gasoline, LPG, Dry Gas and Coke)} versus Length of Reactor

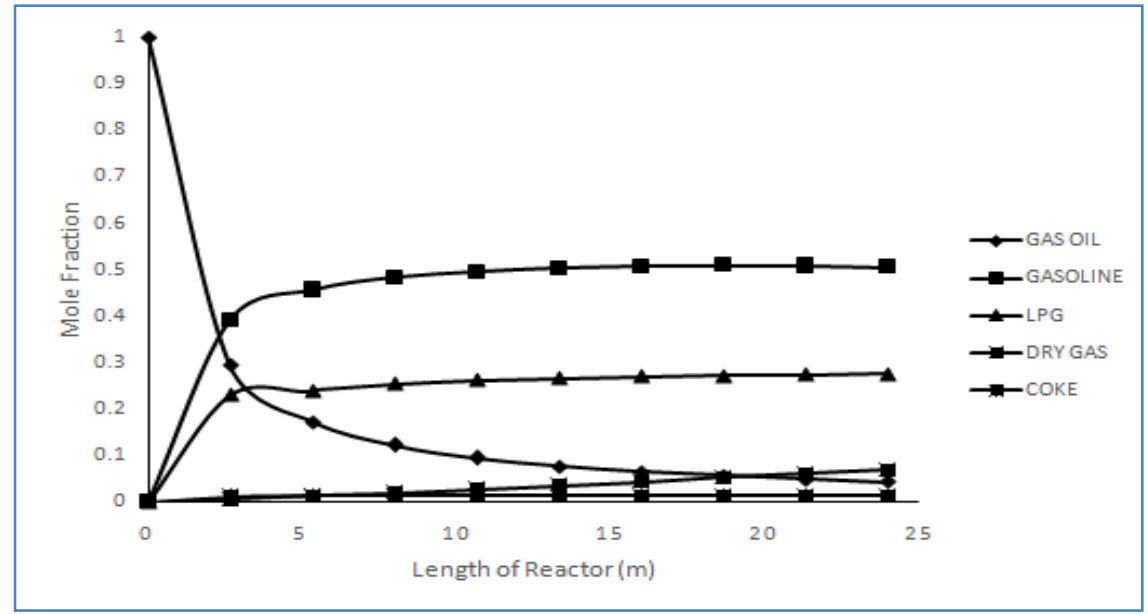

Fig-5: Profile of Optimized Mole Fractions of Cracked Gasoil to different Species (Gasoline, LPG, Dry Gas and Coke) versus Reactor Bed Height

Figure 5 depicts the relationship among the mole fractions of the five (5) lumped models cracked from Gasoil to Gasoline, LPG, Dry Gas and Coke along the riser reactor bed height.

The Gasoil is a second order reactant that was cracked to give Gasoline, Liquefied Petroleum Gas (LPG), Dry Gas and Coke. The depletion by chemical reactions of vacuum gasoil cracked exponentially from $y_{A}=1.00$ to $y_{A}=0.0442$ when $z=0 \mathrm{~m}$ to $z=24 m$ along the riser bed height. The cracked Gasoil produced Gasoline, $\left(y_{B}\right)$; LPG $\left(y_{C}\right)$; Dry Gas $\left(y_{D}\right)$, and Coke $\left(y_{E}\right)$ exponentially along the reactor height with Gasoline yield being the highest. It should be noted that Gasoline is the most desired product needed in this work because it is the most highly demanded product; hence the result shown in Figure 5 indicates the trend and acceptability from the literatures. Coke is seen as the lowest value as the maximum yield was $y_{E}=$ $0.0140 \mathrm{~mol}$ at $z=24 \mathrm{~m}$. This results show that the optimized kinetic parameters (pre-exponential constant and activation energies) generated gave lowest of coke and it's formation as the bottom products. From observation and literatures, the results should be acceptable because it agrees with the trends [20, 19, 14]. The results for the optimized kinetic parameters gave higher products yields compared with the normal process values for gasoline.

\section{Comparison between Gasoline yields for Optimized and Non-optimized Kinetics}

Figure 6 demonstrates the relationship between the mole fractions of gasoline for the non-optimized and optimized results along the reactor bed height. Gasoline formation increased linearly along the length of the reactor as there was cracking and conversion of gas oil to different products. The temperature rate in the reactor favoured greatly the formation of gasoline as it was the most essential product and had the highest formation rate. The highest mole fraction for gasoline from the non-optimized plot was $49 \%$ and $51 \%$ from the optimized plot.

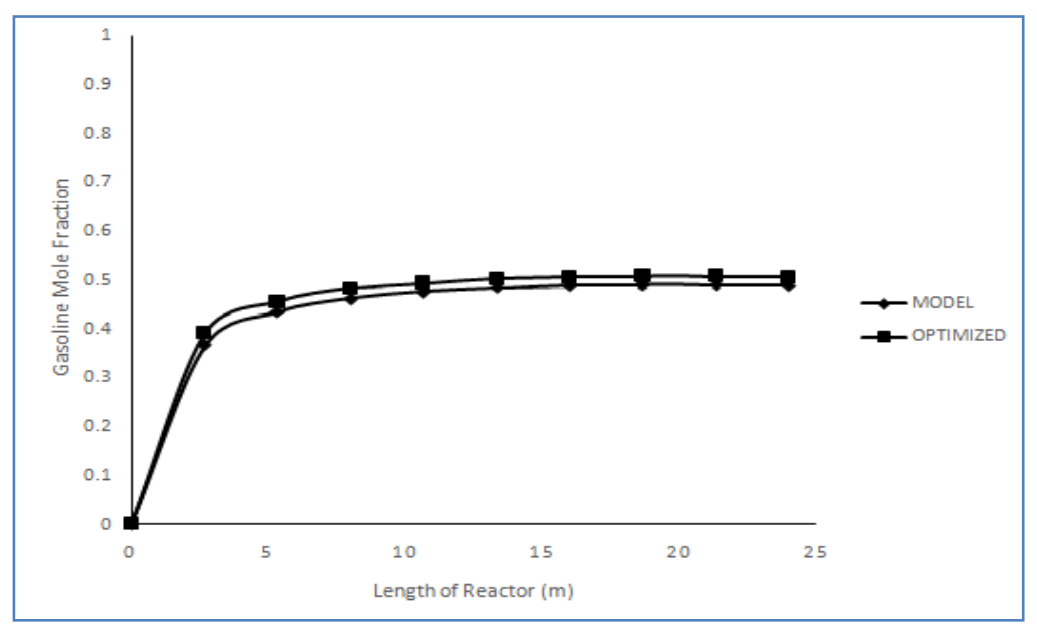

Fig-6: Profile of the Mole Fractions of Cracked Gasoline versus Reactor Length 
It was observed that there was more formation of gasoline) from the optimized plot than the nonoptimized plot, which indicated that optimization of kinetic parameter was necessary and essential for the improvement in the production of gasoline.

\section{Comparison between Optimized and Non-optimized Kinetics for Temperature Profile}

Figure 7 depicts the relationship between Temperature of the riser column and the length of the riser, showing the similarities and differences between the non-optimized and optimized results.

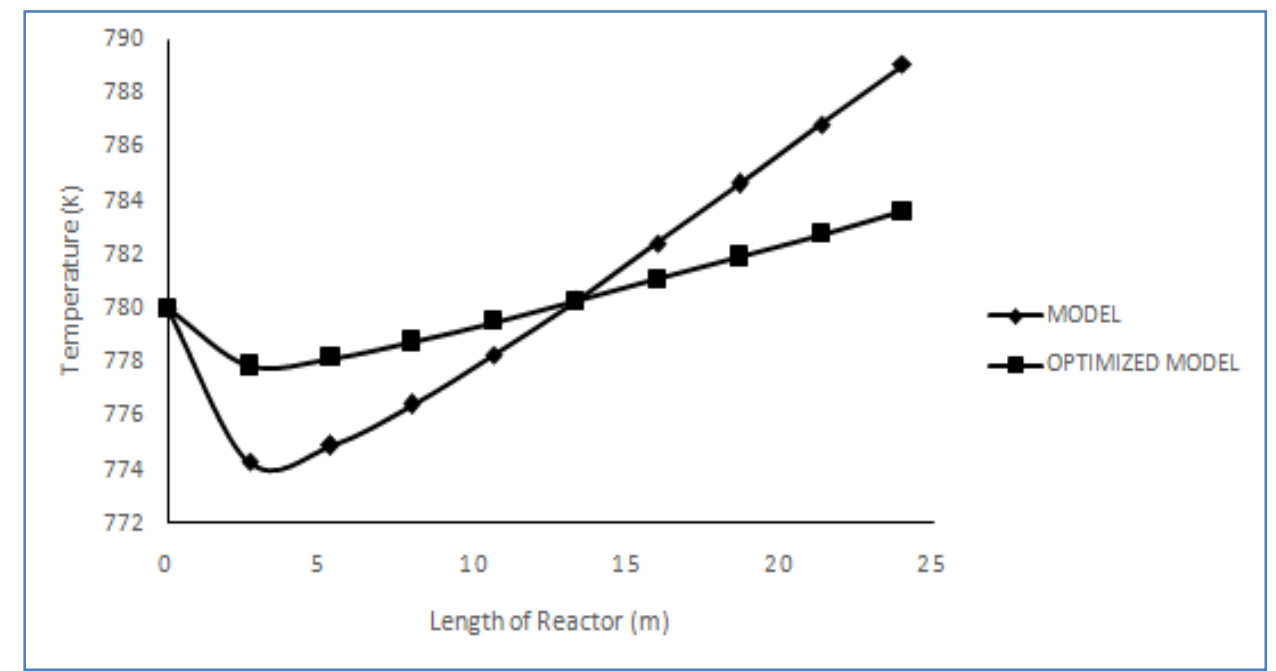

Fig-7:Temperature Profile for optimized and non-optimized Kinetics

The reaction process for the cracking of Gas oil gave products of Gasoline, LPG, Dry gas and coke was an endothermic reaction, initially from $z=0-$ $2.5 \mathrm{~m}$ along the length of the riser column, i.e. very high heat was needed on the convection zone of the riser column at $\mathrm{T}=780 \mathrm{~K}$ for cracking to start and continue. But as the length increased, the heat needed reduced to $\mathrm{T}=774.28 \mathrm{~K}$ for the non-optimized and to $\mathrm{T}=777.86 \mathrm{~K}$ for the optimized plot at $\mathrm{z}=2.5 \mathrm{~m}$. At the Radiation zone, from $\mathrm{z}=2.5-24 \mathrm{~m}$, heat was liberated and more heat was present in excess, which gave rise to the temperature from $\mathrm{T}=774.28 \mathrm{~K}$ to $789.05 \mathrm{~K}$ for the nonoptimized plot and from $\mathrm{T}=777.86 \mathrm{~K}$ to $783.60 \mathrm{~K}$ for the optimized. The maximum temperature from the optimized plot was less than that from the nonoptimized plot because our aim was to reduce cost and maximise profit. The higher the temperature and activation energy, the higher the cost of production and reactor design. There was more heat at the radiation zone due to the fact that the cracking process needed high energy for the activation energy of Gas oil to be broken for products formation. The radiation zone was where more heat was needed, in which excess heat was liberated as a result of heat generated from the combustion of flue gases at the top of the riser. The theory behind the cracking process was that the heat at the convective zone was lower than that at the radiation zone due to flue gas burning which also generate heat together with the heat resulted in the reaction process occurring in the convective zone cause the riser to have excess heat, which agreed with Figure 7.

\section{CONCLUSION}

The research work to Estimate kinetic parameters for five lump Fluid Catalytic Cracking Riser Reactor of Gas Oil has been carried out. Kinetic parameters such as Activation Energies and PreExponential constants estimation were very important as they form the basis of reactor design and the yield of the products considered. The models for the FCC riser were developed using thermodynamic data, material and energy balances principles. Also optimization models were obtained using single regression analysis models and other statistical model such as F-Test. The kinetic parameters were obtained from works of Dagde, 2008 for the simulation of the models using MATLAB version 2018. The results were generated for the five lumped kinetic model where reactant Gasoil as a second order Hydrocarbon was cracked into products (Gasoline, LPG, Dry Gas and Coke) and profiles obtained. The yields in terms of mole fractions of the various components were obtained from the cracked Gasoil in the FCC riser reactor. Then, the results obtained (mole fractions and Temperature result coupled) were then subjected to optimization process model using regression analysis models to obtained the modernized or the optimized kinetic parameters (activation energies, pre-exponential constants and rate constants of the lump) as shown in tables and figures. The optimized kinetic parameters results actually affected the overall results as the optimized values of the parameters improved the yields of the most desired products. The essence of the optimization actually proved to us that improved kinetic parameters can go on 
to improve the yields of the most demanded and economic products and also improving the reactor design. The results were in agreement with the aim and objectives of the research.

\section{REFERENCES}

1. Pedro, J. V. A. (2016). Chemical kinetics; rates of reaction. Cubel Consultancy Presentation, Belize.

2. Paul, F., Klaus, T., Richard L., \& William, R. (2015). General chemistry textbook, produced by Openstax's college. Published by XanEdu Publishing Inc.

3. Elizalde, I., \&Ancheyte, J. (2011). Detailed solution and application of continuous kinetic lumping modelling to hydrocracking of heavy oils. Fuel, 90, 3542-3550.

4. Erdogdu, F. (2008). Optimization in food engineering textbook. $1^{\text {st }}$ Edition, CRC Press Inc, Taylor \& Francis Inc, Bosa Roca, United State, 111-113.

5. Yuceer, M., Atasoy, I., \& Berber, R. (2005). An integration based optimization approach for parameter estimation in dynamic models, European Symposium on Computer Aided Chemical Engineering, 20, 631-636.

6. Levenspiel, O. (1999). Chemical reaction engineering. John Wiley and Sons. Third Avenue, New York. $3^{\text {rd }}$ Edition.

7. Miguel, A. (2016). Modelling of regenerator units in Fluid Catalytic Cracking process. Instituto Superior Tecnio, University Publishing House (IST Press), Lisboa.

8. Yakubu M. J., Mustafa A. M., Raj P., \&Iqbal M. M. (2019). Parameter estimation of a six-lump kinetic model of an industrial Fluid Catalytic Cracking unit. The Science and Technology of Fuel and Energy Journal, 235, 1436-1454.

9. Souza J.A, Vargas J.V.C, Ordonez J.C, Martignoni W.P, \& von Meien, O. F. (2011). Thermodynamic optimization of fluidized catalytic cracking (FCC) units. International Journal of Heat and Mass Transfer, 54, 1187-1197.

10. Sheth, N. P., \&Babu, V. B. (2008). Optimization of kinetic parameters in pyrolysis of biomass using logarithmic differential evolution (LDE). Proceedings of Genetic and Evolutionary Computation Conference, Alanta, Georgia, USA.

11. Dagde, K. K., \&Akpa, J. G. (2014). Development of models for Fluid Catalytic Cracking fluidized bed reactor using four-lump kinetic scheme. IOSR Journal of Engineering (IOSRJEN), 4(12), 22-31.

12. Yakubu, M. J., Raj, P., Iqbal, M. M., \&Mujtaba, U. (2017). Optimization of fluidized catalytic cracking unit regenerator to minimize $\mathrm{CO}_{2}$ emissions. Chemical Engineering Transactions, 57, 15311536.

13. Mu, S.J., Su, H.Y., Li, W., \& Chu, J. (2005). Reactor Model for industrial residual Fluid Catalytic Cracking based on six lump kinetic models. Journal of Chemical Engineering of Chinese University, 19(5), 630-635.

14. Dagde, K. K., \&Puyate, Y.T. (2012). Modelling and simulation of industrial FCC unit: Analysis base on five lump kinetic scheme of gas-oil cracking. International Journal of Engineering Research and Application (IJERA).2(5), 698-714.

15. NPHRC. (1987). New Port Harcourt Refinery Company Limited Operational Manuel.

16. Dagde, K. K., Akpa, J. G., Puyate, Y. T., \&Oboho, E. O. (2008). Five lump kinetic model for Fluid Catalytic Cracking of gas oil in a fluidized bed reactor. Journal of the Nigerian Society of Chemical Engineers, 23.

17. Han, I.S., \& Chung, C.B. (2001). Dynamic modelling and simulation of a fluidized catalytic cracking process. Part 1: Process modelling. Chemical Engineering Science.56(5), 1951-1971.

18. Gupta, A., \&Subba, Rao, D. (2001). Model for the performance of a Fluid Catalytic Cracking (FCC) riser reactor; effect of feed atomization. Chemical Engineering Science, 56, 4489-4503.

19. Ahari, J. S., Farshi, A., \&Forsat, K. (2008). A Mathematical modelling of the riser reactor in industrial FCC unit. Petroleum and Coal Journal,50(2), 15-24.

20. Xu, O., Su, H., Mu, S., \& Chu, J. (2006). 7-Lump Kinetic Model for Residual Oil Catalytic Cracking. Journal of Zhejiong University Science, 11, 19321941.

21. Lee, L. S., Chen, V. W., \& Huang, T. N. (1989). Four Lump Kinetic Model for Catalytic Cracking Process. Canadian Journal of Chemical Engineering, 67, 615-623.

22. Peixoto, F. C., \& Medeiros, J. L. (2001). Reaction in Multi-Indexed Continuous Mixtures; Catalytic Cracking of Petroleum Fractions. American Institute of Chemical Engineers Journal, 47(4), 935-947. 